ARTICLE

Received 23 May 2016 | Accepted 18 Jul 2016 | Published 16 Aug 2016

DOl: 10.1057 /palcomms.2016.56

OPEN

\title{
The prospects for Paris: behavioral insights into unconditional cooperation on climate change
}

David M. McEvoy ${ }^{1,2}$ and Todd L. Cherry ${ }^{1,3}$

\begin{abstract}
Recent survey evidence from the United States suggests that most Americans support domestic policies to address climate change, and this support is not conditional on other countries' commitment levels. The finding is somewhat perplexing because climate change is by definition a collective problem that requires a collective response. However, the question of why Americans support unconditional climate initiatives has not been addressed. We present survey evidence that shows a willingness to act alone is not the result of misunderstanding the collective nature of the climate problem, but rather people are driven by notions of responsibility, morality and global leadership.
\end{abstract}

\footnotetext{
${ }^{1}$ Department of Economics, Appalachian State University, Boone, NC 28608, USA 2 Department of Public Finance, University of Innsbruck, Innsbruck Austria, A-6020 ${ }^{3}$ CICERO Center for International Climate and Environmental Research - Oslo, PB 1129 Blindern, 0318 Oslo, Norway
} 


\section{Introduction}

he twenty-first Conference of the Parties of the United Nations Framework Convention on Climate Change in Paris provided the first truly universal international climate agreement. Whether the Paris agreement is a meaningful step (Friedman, 2015; Harvey, 2015) or just empty promises (Milman, 2015) depends in part on how people view the climate problem. If parties treat climate change as a collective action problem and respond to free-riding incentives (Hoel, 1991; Carraro and Siniscalco, 1993; Barrett, 1994; Nordhaus, 2015), then the collection of pledges that comprise the Paris Agreement warrant a pessimistic outlook. But if parties are willing to act unconditionally, possibly driven by motives beyond material self-interest (Victor, 2014; Kolstad, 2014), the decentralized and flexible approach of Paris may prove fruitful.

For nearly four decades, nearly 200 sovereign countries have gathered to consider how to manage greenhouse-gas (GHG) emissions and avoid dangerous anthropogenic climate change. Efforts began at the first World Climate Conference in 1979 and led to the adoption of the United Nations Framework Convention on Climate Change (UNFCCC) and later the Kyoto Protocol. These efforts followed the understanding that the climate change problem is a social dilemma, one in which individual and collective incentives are misaligned. The social sciences typically model the climate problem as a variant of the prisoners' dilemma, one in which countries are collectively better off reducing GHG emissions, but are individually better off left unconstrained (Barrett, 1994; Nordhaus, 2015). Conventional wisdom developed from theoretical predictions suggests that the problem is unlikely to be solved by unilateral action; rather, mitigating climate change requires global collective action. Garrett Hardin's classic "Tragedy of the Commons" characterizes the necessary collective action as "mutual coercion, mutually agreed upon" (Hardin, 1968). This perspective shaped the UNFCCC goals of pursuing a centrally negotiated international agreement that would motivate comprehensive participation, set targets with deep commitments, and create enforcement mechanisms to ensure widespread compliance. Unfortunately, an effective comprehensive "top-down" solution to the climate problem has been elusive-for example, global carbon dioxide emissions have increased by more than $50 \%$ since the adoption of the UNFCCC in 1992 (Olivier et al., 2014).

In response, experts have shifted their attention to exploring alternatives to the idyllic comprehensive top-down climate agreement architecture. One point of departure is to pursue a much less inclusive approach; one that concentrates on the handful of countries that account for the majority of global emissions (Victor et al., 2005; Victor, 2006). Similarly, recent efforts have suggested the idea of climate clubs-agreements among a limited number of governments that link climate action to other policy dimensions that reward membership (for example, trade tariffs) (Stewart et al., 2013; Falkner, 2015; Nordhaus, 2015). These kinds of approaches seek progress by sacrificing inclusivity, but they remain built on the standard theoretical prescriptions for a collective action problem.

The Paris Agreement breaks from conventional thinking by not including key elements that are typically presumed necessary for meaningful international environmental agreements. There is no agreed upon global emissions target that is divided into individual responsibilities. Countries have autonomy and flexibility to set and meet emission reductions in the context of their national priorities, circumstances and capabilities. And participation and compliance are essentially non-binding with stated expectations and public review providing social pressure as a soft enforcement mechanism. The Paris Agreement achieves "mutual agreement" but without "mutual coercion". Critics, drawing from the standard collective action framework, naturally conclude that Paris is a series of empty promises that are bound to succumb to free-riding.

The climate problem, however, may have aspects that challenge the standard collective action framework. Research clearly demonstrates that the context and framing of a collective action problem affects the level of cooperation (for example, Tversky and Kahneman, 1981; Ostrom, 2000), and this seems particularly relevant for a problem as socially and politically complex as climate change. Negotiations between parties are just as likely to focus on issues of equity, fairness and responsibility, as they are to address the monetary benefits and costs of emissions abatement. Considering such non-pecuniary concerns, individual incentives might be more aligned with collective interests than presumed in the standard game-theoretic framework. The notion that some parties may act unilaterally is particularly relevant in a repeated context like climate change because previous studies suggest that initial actions can facilitate reciprocal actions by others (Axelrod and Hamilton, 1981; Arce, 2001) and the formation of willing groups or climate clubs (Victor, 2011; Hovi et al., 2016).

Whether the Paris agreement is a meaningful step or just empty promises depends in part on how the participants approach the climate problem. If parties treat climate change as a collective-action problem that leads to free-riding, then the lack of incentives to cooperate along with a weak enforcement mechanism warrant a pessimistic outlook. But if parties are willing to act unilaterally, the menu of promising climate agreement architectures may not require mechanisms that prevent free-riding. The need for mutual coercion may be overstated, and by discounting non-pecuniary motives, the benefits of individual action may be undersold.

We consider the role of non-pecuniary concerns-those beyond maximizing one's own material payoffs-in the climate change problem and therefore the possibility that standard gametheoretic models may not fully characterize the climate problem. We report survey results that reveal how Americans view the climate change problem, the extent to which they support unilateral domestic action to reduce GHG emissions, and the reasons that govern their support for unilateral action.

\section{Methods}

Our survey was administered online through Qualtrics and the sample was drawn from Amazon Mechanical Turk (United States respondents) in January 2016. Respondents first answered questions regarding their beliefs on whether climate change is happening, whether it is caused by human activity and what level priority should addressing climate change be given at the national level (see Supplementary Information for the survey questions and additional statistics). The question about whether respondents support domestic action to address climate change and whether that support is conditional on the actions of other countries was borrowed from (Leiserowitz et al., 2015). We ask the following question (which we refer to as the policy question):

People disagree whether the United States should reduce greenhouse gas emissions on its own, or make reductions only if other countries do so. Which of the following statements comes closest to your own point of view? The United States should reduce its greenhouse gas emissions...

1. Regardless of what other countries do

2. Only if other industrialized countries (such as England, Germany and Japan) also reduce their emissions

3. Only if other industrialized countries AND developing countries (such as China, India and Brazil) also reduce their emissions

4. The US should not reduce its emissions

5. Don't know/refuse

The large and consistent support for unilateral domestic climate policy found in the literature (Bernauer and Gamfer, 2015; Borick et al., 2015; Leiserowitz et al., 2015) (and confirmed here) suggests that climate change is not a collective action problem in the American mind. Unconditional support for climate policies has also been reported in other developed and developing countries (Tingley and Tomz, 
2014). The result is somewhat perplexing because climate change is by definition a collective problem and its solution will require a collective response. In order to shed light on the motives behind these preferences to act alone, we designed a splitsample survey to investigate whether the stated willingness to act is based on informed preferences or a naiveté arising from not understanding the strategic nature of the problem.

The survey design entails two features for this purpose. First, after respondents answered the question above, they answered six true/false questions to assess their understanding of the collective nature of the climate problem (see Supplementary Information). The number of correctly answered questions serves as a measure of understanding. Second, the sample was split between two versions of the surveyan information version provided an explanation of the collective nature of the climate problem before delivering the questions above (see Supplementary Information), while a no information version did not provide an explanation.

In total 352 respondents participated in one of two treatments- 177 in the no information treatment and 175 in the information treatment. All respondents reside in the United States and earned US $\$ 0.90$ for completing the survey, which required less than $10 \mathrm{~min}$ on average to complete. For our analyses, the key demographic variables in our sample were weighted, post survey, to match U.S. Census Bureau norms. The sample demographics, survey questions and summary statistics are included in the Supplementary Information. This study was approved by the Institutional Review Board at Appalachian State University (\#14-0272). Participants indicated their consent by opting into the online survey and the data were analyzed anonymously.

\section{Results}

Consistent with other recent surveys that solicit American opinions on climate change (Borick et al., 2015; Leiserowitz et al., 2015), the majority of respondents in our survey believe that climate change is happening (78.7\%) with a smaller percentage believing that climate change is caused, in part, by human activity $(65.4 \%)$, and $60 \%$ of respondents consider climate change a very high or high national priority.

The responses to the policy question soliciting American's willingness to support national reductions in GHG emissions are summarized in Fig. 1. Most Americans (79.4\%) support the United States taking action to reduce GHG emissions regardless of what steps other countries take (option \#1 from question above). Mirroring Leiserowitz et al. (2015), we find that roughly $12 \%$ of respondents think the United States should only take action conditional on other countries making similar efforts (5.7\% require other developed countries to act and 6.3\% require both developed and developing countries to take action). A small fraction of people stated that the United States should not reduce GHG emissions (5.4\%) and 3.2\% did not know or refused to answer. The results suggest that most people do not require a collective global response to climate change in order to support domestic policies to reduce GHG emissions. The climate change problem does not appear to be a collective action problem in the American mind, and the widespread willingness to act alone gives some hope that a successful climate agreement does not hinge on mechanisms to counteract tendencies to free-ride.

Figure 1 also breaks down the reasons respondents give for having a willingness to act alone. The most frequent reason given (35.9\%) is that the United States should lead by example on addressing climate change (Leadership). About one third (31.3\%) believe that addressing climate change is morally the right thing to do (Morals) and $14.1 \%$ believe the United States should reduce GHG emissions because the United States bears a lot of responsibility for climate change (Responsibility). The remainder is either willing to support unilateral action because of the possibility of energy independence $(7.8 \%)$, to gain an economic advantage $(5.1 \%)$ or because they believe the United States could adequately protect itself from climate change by acting along (5.8\%). The majority of respondents support unilateral action for non-pecuniary concerns about climate change-incentives that exist outside the standard collective action framework.

The support for unilateral climate action in our sample corresponds to previous reports and actual legislation (Bernauer and Gamfer, 2015; Leiserowitz et al., 2015; Nachmany et al., 2015). However, we dig a bit deeper to find that the reasons for acting alone lie outside the standard collective action framework. The findings may suggest that free-riding may not be as central to the problem as many presume, but alternatively the findings may be an artefact of people not understanding the strategic nature of the climate problem. Is support for unilateral action based on informed preferences or confusion? This matters because it speaks to the stability of people's willingness to act alone. If people understand the problem, their support is relevant to domestic action and climate architectures. But if confused, people may adopt a conditional stance on climate policy after they learn more about the collective nature of the climate problem.

Answers to the comprehension questions show that respondents have a good baseline understanding of the collective nature of GHG emissions and the related interdependencies between nations. In the no information treatment, respondents answered $69.5 \%$ (4.17 of 6.0 ) of questions correctly on average, with $11.3 \%$ of them getting a perfect score. Results from the information treatment reveals this baseline understanding is improved when respondents are provided an explanation of the climate problem.
Reasons why the U.S. should act to reduce GHG emissions regardless of other countries

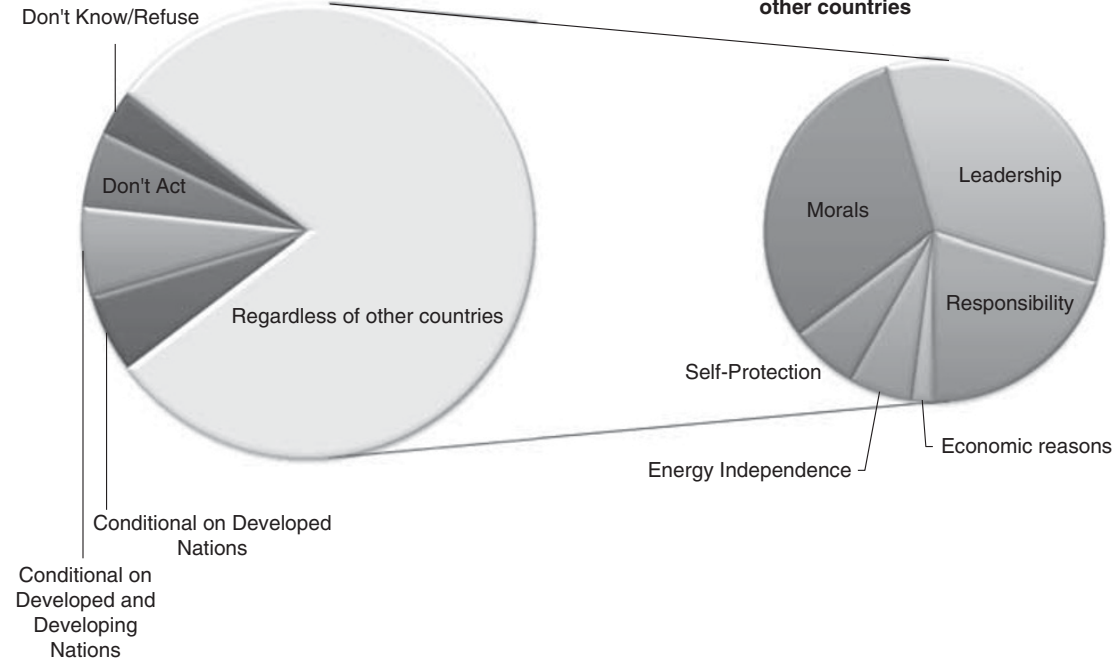




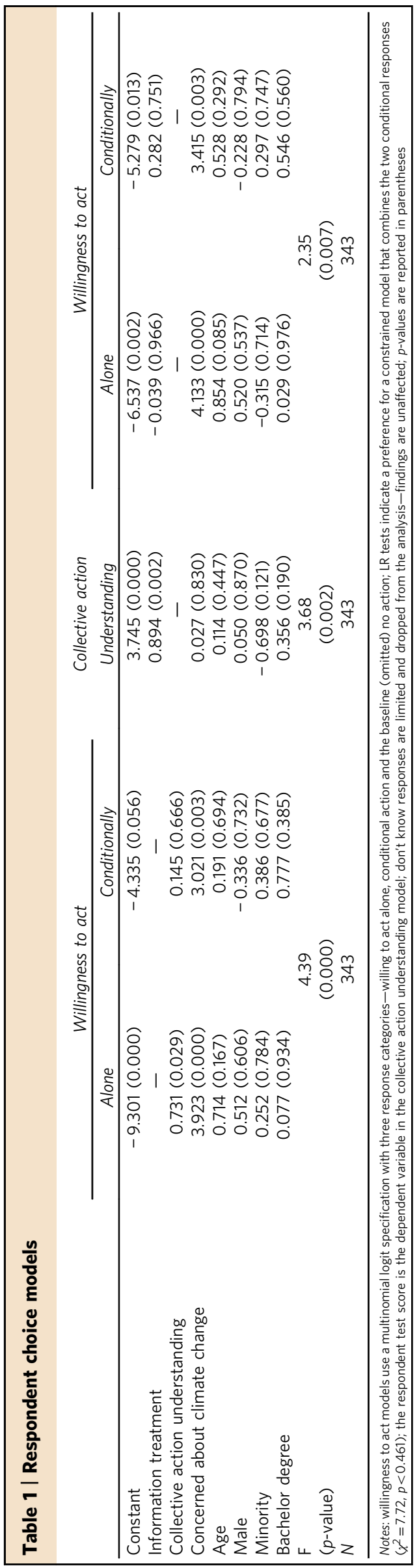

Average scores in the information treatment increased to $82.2 \%$ (4.93 of 6.0) and the per cent of perfect scores jumped to $36.6 \%$ relative to the no information treatment.

We conduct conditional analyses to examine how a person's understanding of the climate problem might explain her support for unilateral domestic climate action. From the design, we examine three questions concerning the relationship between people's understanding of the collective nature of the climate problem and their willingness to act alone to address the problem.

First, we test whether respondent ex ante understanding of the collective nature of the climate change problem explains support for unilateral domestic climate action. The first two columns in Table 1 contain estimates for the following multinomial model:

Policy $_{i}=\beta_{0}+\beta_{1}$ Understanding $_{i}+\theta^{\prime} X_{i}+\varepsilon_{i} \quad i=1,2 \ldots N$

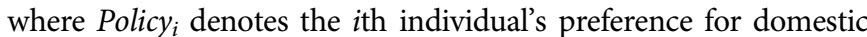
climate policy (five options: unconditional, conditional on other industrial countries acting, conditional on all other countries acting, no action regardless and don't know/refuse); Understanding $_{i}$ is the number of correct answers that respondent $i$ provided to the six comprehension questions; $X_{i}$ is a vector of control variables; $\varepsilon_{i}$ is the well-behaved error term. Two items are noted. One, LR tests indicate a preference for a constrained model that combines the two conditional responses $\left(\chi^{2}=7.72\right.$, $p=0.461)$. Two, due to the limited numbers of don't know/ refuse responses (9 of 352), we drop them from the analysis. Neither step alters the findings, but they do simplify the policy choice set to three options: unconditional, conditional and no action (no action omitted baseline).

We find that a person's baseline understanding of the collective nature of the problem is a significant predictor of whether a person supports unilateral climate policy. From the first column in Table 1, people that have a better understanding of the collective problem are more likely to support unilateral action $(p=0.029)$. While perhaps counter-intuitive, the finding is consistent with empirical evidence that better understanding leads to more cooperation over time, not less (Ostrom, 2000). The results also suggest that greater concern about climate change leads to a stronger willingness to act (either alone or conditionally relative to not acting at all). Moreover, as illustrated in Table 2, the data suggest that increased understanding is correlated with increased reliance on non-pecuniary factors. Table 2 shows that understanding the problem is associated with the "more altruistic" motives (leadership, morality, responsibility) rather than the "more strategic" motives (economic, independence, selfprotection).

Next, we test whether providing information about the collective nature of the climate problem increases respondent understanding of the problem. The middle column in Table 1 reports estimates from the following linear probability model:

$$
\begin{aligned}
\text { Understanding }_{i}= & \beta_{0}+\beta_{1} \text { Information }_{i}+\theta^{\prime} X_{i}+\varepsilon_{i} \\
& i=1,2 \ldots N
\end{aligned}
$$

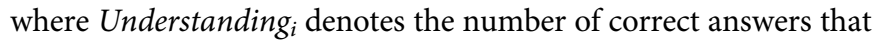
respondent $i$ provided to the six comprehension questions; Information $_{i}$ is an indicator variable that signifies whether the $i$ th respondent received the information treatment survey ( 1 if yes; 0 if no). From Table 1, we see that respondents whoreceived an explanation of the collective nature of the climate problem performed significantly better on the comprehension questions $(p=0.002)$.

Finally, we test whether providing information about the collective nature of the climate problem (which increased understanding) changes respondent support for unilateral domestic climate action. We estimate the following multinomial 


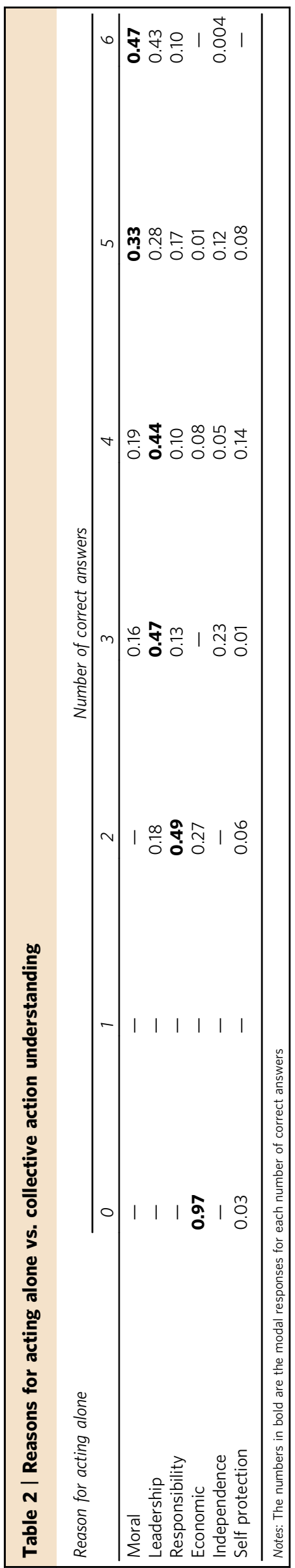

logit model of respondent policy preference:

$$
\text { Policy }_{i}=\beta_{0}+\beta_{1} \text { Information }_{i}+\theta^{\prime} X_{i}+\varepsilon_{i} \quad i=1,2 \ldots N
$$

where Policy $y_{i}$ denotes the $i$ th individual's preference for domestic climate policy (same three options as the initial model); Information $_{i}$ is an indicator variable that signifies whether the $i$ th respondent received the information treatment survey ( 1 if yes; 0 if no). The estimates for this model are found in the last two columns in Table 1 . The results demonstrate that while providing an explanation significantly improved respondents' understanding of the climate problem, it does not affect their support for climate policy (either acting alone or conditionally). Results therefore provide convincing evidence that the widespread support for unilateral climate action is not based on a poor understanding of the collective nature of the problem.

We note two additional results. While concern about climate change does not affect respondents' understanding of the problem $(p=0.830)$, it does significantly affect their willingness to act (either alone or conditionally) in both models $(p<0.01)$. And, all three models were alternatively estimated after dropping data from respondents who do not believe climate change is happening (from Question 1). The main findings do not change.

\section{Discussion}

Though far from definitive, our findings offer some reasons to think the Paris Agreement is more than empty promises. We find the climate problem may be more distant from the characterizations found in standard game-theoretical models. Despite the strategic nature of GHG mitigation, free-riding may not be as central to the problem as these models presume. We find widespread support for unconditional domestic action on climate change, and we find this willingness to act alone is not based on naiveté-rather, it appears to be associated with an awareness of the collective nature of the problem. We find the unconditional preference is built on appropriate non-pecuniary considerations such as leadership, fairness and morality. Though such considerations may be marginal in many collective action problems, they appear to matter a great deal in the climate problem.

Managing climate change does not appear to be a collective problem in the American mind. Previous studies and actual legislative actions reveal similar views exist in developing and developed countries (for example, Nachmany et al., 2015; Tingley and Tomz, 2014). The implication is that much of the strategic game-theoretic modeling of the climate problem has been grounded in an incomplete formulation of country-level preferences. Given preferences beyond material self-interest, resolving the climate problem may be less prone to free-riding than the standard prisoners' dilemma model predicts. The existence and persistence of the climate change problem demonstrate that externalities and free-riding matter, but as people's understanding of climate change evolves, they may increasingly view the problem as a moral issue as much as a strategic game. While this and other studies rely on survey methods that abstract away from details and consequentiality, actual unilateral policies undertaken by individual states and regions corroborate an interest in unilateral action on climate change.

This study offers evidence on why people support unilateral action, and the findings raise questions about the correspondence between the climate problem and standard game-theoretical modelling. The findings also add to existing arguments that the Paris agreement may be a meaningful step forward (for example, Victor, 2015). However, there is no ignoring the fundamental incentives that invite inadequate climate action by individual 
countries. Thus, while Paris may surprise the critics, its ultimate success depends on how it encourages more ambitious efforts over time.

\section{References}

Arce MDG (2001) Leadership and the aggregation of international collective action. Oxford Economic Papers; 53 (1): 114-137.

Axelrod R and Hamilton WD (1981) The evolution of cooperation. Science; 211 (4489): 1390-1396.

Barrett S (1994) Self-enforcing international environmental agreements. Oxford Economic Papers; 46 (1): 878-894.

Bernauer T and Gamfer R (2015) How robust is public support for unilateral climate policy? Environmental Science and Policy; 54 (December): 316-330.

Borick C, Rabe BG and Mills SB (2015) Acceptance of global warming among Americans: Researches its highest level since 2008. A Report from the National Surveys on Energy and Environment. University of Michigan: Ann Arbor, MI.

Carraro C and Siniscalco D (1993) Strategies for the international protection of the environment. Journal of Public Economics; 52 (3): 309-328.

Falkner R (2015) International negotiations: Towards minilateralism. Nature Climate Change; 5 (9): 805-806.

Friedman TL (2015) Paris climate accord is a big, big deal. The New York Times 16 December.

Hardin G (1968) Tragedy of the commons. Science; 162 (3859): 1243-1248.

Harvey F (2015) Paris climate change agreement: the world's greatest diplomatic success. The Guardian 14 December.

Hoel M (1991) Global environmental problems: The effects of unilateral actions taken by one country. Journal of Environmental Economics and Management; 20 (1): 55-70.

Hovi J, Sprinz DF, Sælen H and Underdal A (2016) Climate change mitigation. A role for climate clubs? Palgrave Communications; 2:16020 doi: 10.1057/ palcomms.2016.20.

Kolstad C (2014) International environmental agreements among heterogeneous countries with social preferences. NBER working paper No. 20204, June.

Leiserowitz A, Maibach E, Roser-Renouf C, Feinberg G and Rosenthal S (2015) Climate Change in the American Mind: October, 2015; Yale Program on Climate Change Communication Yale University and George Mason University: New Haven, CT.

Milman O (2015) James Hansen, father of climate change awareness, calls Paris talks 'a fraud' The Guardian 23 December.

Nachmany M et al (2015) The 2015 Global Climate Legislation Study: A Review of Climate Change Legislation in 99 Countries. GLOBE International and the Grantham Research Institute, London School of Economics: London.
Nordhaus W (2015) Climate clubs: Overcoming free-riding in international climate policy. American Economic Review; 105 (4): 1339-1370.

Olivier JGJ, Janssens-Maenhout G, Muntean M and Peters J.H.A.W. (2014) Trends in Global CO2 Emissions: 2014 Report, JRC report 93171/PBL report 1490; ISBN 978-94-91506-87-1.

Ostrom E (2000) Collective action and the evolution of social norms. Journal of Economic Perspectives; 14 (3): 137-158.

Stewart RB, Oppenheimer M and Rudyk B (2013) A new strategy for global climate protection. Climatic Change; 120 (1): 1-12.

Tingley D and Tomz M (2014) Conditional cooperation and climate change. Comparative Political Studies; 47 (3): 344-368.

Tversky A and Kahneman D (1981) The framing of decisions and the psychology of choice. Science; 211 (4481): 453-458.

Victor DG (2006) Toward effective international cooperation on climate change: Numbers, interests and institutions. Global Environmental Politics; 6 (3) $90-103$.

Victor DG (2011) Global Warming Gridlock: Creating More Effective Strategies for Protecting the Planet. Cambridge University Press: Cambridge, UK.

Victor DG (2014) Copenhagen II or something new? Nature Climate Change; 4 (10): 853-855.

Victor DG (2015) Approach to climate diplomacy. Yale Environment 360, 15 DecemberXG.

Victor DG, House JC and Joy S (2005) A madisonian approach to climate policy. Science; 309 (5742): 1820-1821.

\section{Data availability}

The data generated in this study are available at the author's website (http://www.appstate.edu/ mcevoydm/UnderstandingParis_DATASET.xlsx).

\section{Additional information}

Supplementary Information: accompanies this paper at http://www.palgrave-journals .com/palcomms

Competing interests: The author declares no competing financial interests.

Reprints and permission information is available at http://www.palgrave-journals.com/ pal/authors/rights_and_permissions.html

How to cite this article: McEvoy D, Cherry T (2016) The prospects for Paris: behavioral insights into unconditional cooperation on climate change. Palgrave Communications. 2:16056 doi: $10.1057 /$ palcomms.2016.56.

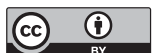

This work is licensed under a Creative Commons Attribution 4.0 International License. The images or other third party material in this article are included in the article's Creative Commons license, unless indicated otherwise in the credit line; if the material is not included under the Creative Commons license, users will need to obtain permission from the license holder to reproduce the material. To view a copy of this license, visit http://creativecommons.org/licenses/by/4.0/ 